\title{
Analysis of Sesquiterpene Distributions in the Leaves, Branches, and Trunks of Avocado (Persea americana Mill.)
}

\author{
Jerome Niogret, Nancy D. Epsky, Elena Q. Schnell, Raymond J. Schnell, Robert R. Heath, \\ Alan W. Meerow, Paul E. Kendra*
}

Subtropical Horticulture Research Station, Agricultural Research Service, United States Department of Agriculture, Miami, USA. Email: "paul.kendra@ars.usda.gov

Received March $8^{\text {th }}, 2013$; revised April $3^{\text {rd }}, 2013$; accepted April 13 ${ }^{\text {th }}, 2013$

Copyright (C) 2013 Jerome Niogret et al. This is an open access article distributed under the Creative Commons Attribution License, which permits unrestricted use, distribution, and reproduction in any medium, provided the original work is properly cited.

\begin{abstract}
Avocado is a commercially valuable fruit crop cultivated in tropical and subtropical climates throughout the world. Taxonomists recognize three horticultural races of avocado, consisting of Mexican (Persea americana var. drymifolia), Guatemalan (P. americana var. guatemalensis), and West Indian (P. americana var. americana) varieties. Published research that attempted to differentiate among the horticultural races by using leaf chemistry found that sesquiterpene content was only useful for discrimination of pure Mexican from Guatemalan and West Indian, but not to distinguish between Guatemalan and West Indian races. This study presents a sampling method for analysis of sesquiterpenes from avocado leaf, branch and trunk samples. Our results indicate that sesquiterpene content from leaves and small diameter branches $(<2.5 \mathrm{~cm})$ was highly variable; however, sesquiterpenes were much less variable within wood from larger diameter branches and trunk samples, providing information representative of avocado varietal differences. In addition to chemotaxonomic applications, information on sesquiterpene content of avocado wood is needed for identification of host-based attractants for a new avocado pest, the redbay ambrosia beetle (Xyleborus glabratus). This insect vectors a fungal pathogen that causes laurel wilt, a lethal vascular disease that currently threatens avocado production in south Florida, USA. Females of $X$. glabratus identify appropriate host trees based on emissions of terpenoids, particularly $\alpha$-copaene. Our results are discussed in terms of how proximo-distal distributions of sesquiterpenes may function as host-location cues by this invasive wood-boring pest.
\end{abstract}

Keywords: Avocado; Persea americana; Sesquiterpenes; $\alpha$-Copaene; Redbay Ambrosia Beetle; Xyleborus glabratus

\section{Introduction}

The avocado, Persea americana Mill., is a tree native to the Caribbean, Mexico, Central and South America that is classified in the angiosperm family Lauraceae. Fruit produced by this tree is unique and nutritious. The fruit was known by the Aztecs as "ahuacacuauhitl", which was later shortened by the Spaniards to "aguacate". Avocado is a commercially valuable crop that is cultivated in tropical and sub-tropical climates throughout the world. Avocado was introduced into Florida in 1833, into California in 1848 and into Hawaii by 1855 [1]. In the United States, major commercial production of avocado is limited to California and Florida. In 2004, global production exceeded 3.4 million metric tons and major producers were Mexico, Indonesia, United States and Colombia [2]. Avocado is the most important tropical fruit

"Corresponding author. crop in Florida. Commercial production, which is centered in Miami-Dade County, occurs on over 2800 ha, employs 1000 workers, and is valued at \$30 million per year. Avocado is also the most important fruit tree for homeowners in South Florida and a major component of the urban tree canopy. As part of the National Germplasm System, the Clonal Repository at USDA-ARS Subtropical Horticulture Research Station (SHRS, Miami, Florida) maintains the national germplasm collections of tropical and subtropical plants, including avocado. The SHRS collection contains over 270 accessions of mature avocado trees [3] that include representatives from the three horticultural races (Mexican, P. americana var. drymifolia; Guatemalan, P. americana var. guatemalensis; West Indian, P. americana var. americana) as well as numerous hybrids among them [4]. The earliest introductions were collected by Wilson Popenoe in Guatemala in the 1920s [5], and the newest introductions were 
collected by Avraham Ben-Ya'acov throughout Central and South America during the 1990s [6].

Avocado trees are currently threatened by a fungal pathogen vectored by an exotic wood-boring insect, the redbay ambrosia beetle (RAB), Xyleborus glabratus Eichhoff (Coleoptera: Curculionidae: Scolytinae) [7]. First detected in the US near Savannah, Georgia in 2002, the beetle and it fungal symbiont, Raffaelea lauricola T.C. Harr. Fraedrich \& Aghayeva [8], have since caused substantial mortality of native redbay (Persea borbonia (L.) Spreng.) and swampbay (P. palustris (Raf.) Sarg.) trees throughout six states within the southeastern Coastal Plain [9]. Redbay mortality was first reported in north Florida in 2005, and the insect/fungus complex quickly spread southward to reach the avocado production areas in south Florida by the Spring of 2012 [10]. RAB does not feed on wood, but carves out galleries in host trees. During the boring process, the host is inoculated with Raffaelea spores carried in the beetle's mandibular mycangia [7]. The resultant fungal growth serves as food for $\mathrm{RAB}$, but it also elicits a defensive response that blocks the host xylem, causing infected trees to wilt and die within several weeks or months [7]. Referred to as laurel wilt, this vascular disease is known to affect other plants in the Lauraceae, including avocado [11]. It is the first ambrosial fungus that is considered an aggressive tree pathogen, and it is thought to be capable of colonizing an entire tree from a single introduction point (i.e., just one beetle attack) [8]. The laurel wilt epidemic, including our current understanding of the mycopathogen, the insect vector, and the susceptible host trees has been the subject of a recent review [12].

The threat to commercial avocado has led to an increased need for effective attractants for early detection and monitoring of RAB. To date, no pheromones have been identified for $\mathrm{RAB}$, and initial research indicated that host tree volatiles (kairomones) may be the best source of RAB attractants [13]. Identification of volatile emissions from redbay bolts suggested that $\alpha$-copaene was the primary attractant, but calamenene was also hypothesized to be involved [14]. These sesquiterpenes $\left(C_{15}\right.$ hydrocarbons) are not readily available as synthetic chemicals (and when available, are prohibitively costly), and consequently are not feasible for incorporation into a field lure for RAB. However, two plant essential oils high in $\alpha$-copaene were found to be attractive to RAB, consisting of manuka oil (extracted from the New Zealand manuka tree, Leptospermum scoparium Forst. and Forst., Myrtaceae) and phoebe oil (extracted from the Brazilian walnut tree, Phoebe porosa Mex., Lauraceae) [14]. Field evaluations conducted in Florida found phoebe oil lures to be highly attractive to RAB, with a field life of 2 - 3 months $[15,16]$, but unfortunately phoebe oil is no longer available commercially. Manuka oil lures were found to be attractive initially, but the lures lost efficacy after $2-3$ weeks due to rapid loss of sesquiterpenes $[15,16]$. Therefore, there is a critical need to identify better attractants for development of an improved field lure for RAB.

We report herein studies to identify volatile chemicals from avocado plant material that could be used by RAB for host location. Published chemical analyses of manuka oil indicated a high degree of variability within and among extracts from trees of different geographic regions, but that sesquiterpenes were consistently the predominant components $(\geq 60 \%)$ [17]. Therefore studies were conducted to develop a sampling method to 1) identify and quantify sesquiterpenes present in avocado plant material; 2) document how these chemicals are distributed throughout the tree from leaf to trunk; and 3) compare chemical content from trees that represent different parental races. For comparative purposes, the volatile chemical profile of manuka oil was also obtained. In addition to identification of semiochemicals for RAB, the information on sesquiterpene content will facilitate avocado taxonomic studies. Therefore, this study also examined the avocado samples for presence of anethole and its double-bond isomer estragole, since they had been shown previously to have chemotaxonomic relevance [18].

\section{Materials and Methods}

\subsection{Plant Material}

Plant samples were collected from mature avocado trees at SHRS with genotypes that represent all three races. Cultivars included a "Simmonds" (West Indian; W2-2, MIA\# 7831, PI\# 36270, received 1913), which is the most common cultivar used for commercial production in south Florida [19], a "Seedless Mexican" (Mexican race; W4-1-08-15, MIA\# 2684, PI\# 32400, received 1912, planted 1930), and two seedlings that were planted in June 1995 as part of a selection trial for late fruiting genotypes. The seedlings were obtained from an open pollinated "Melendez" (West Indian/Guatemalan hybrid; W3-1-06-01, MIA\# 19770, received 1966). It is not known if the seedlings are hybrids with other cultivars or from self-pollination of the "Melendez", so they are referred to as "Melendez" seedlings in this report.

Branches were cut from trees to provide both leaf and branch samples. Leaf samples were obtained by collecting 8 - 10 leaves from the branch. Leaves were separated from petioles, were cut into sections $\left(1.2 \mathrm{~cm}^{2}\right)$, and petioles were discarded. Initial tests were conducted with leaves from one of the "Melendez" seedlings to compare chemical collection by SPME verses Super-Q (see below). Samples of leaves were obtained from five branches (replicates). Each sample was divided into two subsets, 
and paired collections were made using SPME and Super-Q. Subsequent tests used a different "Melendez" seedling for comparisons among genotypes. Branch samples were obtained using a lathe (TurnCrafterPro Midi Lathe [\#9908] equipped with a duplicator [\#1806]; The Wooden Post, Joshua, Texas, USA) to remove layers from the branch circumference by shaving to incremental depths. Initial tests determined location of volatile chemicals within the cross-section of a branch. For this, thin layers that included cambial tissue (sequentially bark, cork cambium, phloem, vascular cambium, xylem separately) and pith were sampled from branches (2.54 - 5.08 $\mathrm{cm}$ in diameter). For convenience, we will refer to these tissues collectively as "cambial". Shavings obtained by lathing were collected on a Teflon sheet. Subsequent tests compared volatile chemicals among branch material from the three genotypes. For these comparisons, all cambial tissue was obtained by lathe from sequential sections (20 cm long) of branches that were $0.8,1.3,2.5$, 3.8 and $5.1 \mathrm{~cm}$ in diameter.

Trunk samples were obtained by boring into the main trunk with a forstner drill bit $(0.635 \mathrm{~cm}$ diam $)$ to a depth of approximately $0.635 \mathrm{~cm}$. Forstner drill bits were used to obtain samples from holes with clean edges and flat bottoms. Shavings obtained by drilling were collected on a Teflon sheet and included cambial tissue primarily. One branch per tree was used per replicate, and material for leaf and branch samples were obtained from the same branch. Three replicates of leaf, branch and trunk samples were obtained from a single tree of each genotype.

\subsection{Manuka Oil}

Manuka oil lures were obtained from Synergy Semiochemicals Corporation (Burnaby, British Columbia, Canada). Manuka oil was obtained from Harmonic Skin Tones (Fallbrook, California, USA) as neat (undiluted) material.

\subsection{Chemical Collection and Analysis}

Volatile chemicals were collected using Solid Phase Microextraction (SPME) with a $100 \mu \mathrm{m}$ polydimethylsiloxane coating (non-bonded) fiber (Supelco, Bellefonte, PA). Sampled substrates were placed into beakers sealed with Parafilm M (Thomas Scientific, Swedesboro, New Jersey, USA) and held at room temperature for $1 \mathrm{hr}$ prior to sampling. A sample was obtained by inserting the SPME fiber through a small hole in the parafilm and exposing the fiber to headspace volatiles for $5 \mathrm{~min}$. For comparative purposes and to quantify the sesquiterpenes, volatile chemicals were also sampled using collector traps with Super-Q as the adsorbent (Analytical Research Systems, Inc., Gainesville, Florida, USA) using methods described previously $[20,21]$. Samples were placed in modified glass chambers ( $38.1 \mathrm{~cm}$ long and $11.4 \mathrm{~cm} \mathrm{ID)}$, purified air was introduced into the chamber $(1 \mathrm{Li}-$ ter/min), and volatile chemicals collected for $15 \mathrm{~min}$. Collector traps were cleaned by soxhlet extraction using methylene chloride for $24 \mathrm{~h}$ and dried in a fume hood prior to use. Volatiles were eluted using $100 \mu \mathrm{l}$ of high purity methylene chloride. Prior to chemical analysis, sample extracts were concentrated with slightly elevated temperature. All chemicals were collected within $6 \mathrm{hr}$ of sampling the plant material.

Volatiles collected were analyzed using several types of gas chromatography-mass spectroscopy (GC-MS) systems. Initially, tentative identification of the sesquiterpenes was done on an Agilent ${ }^{\circledR}$ GC-MS from Agilent Technologies (Santa Clara, California, USA) using electron impact ionization. The system is a $6890 \mathrm{~N}$ Network GC system interfaced to a 5975B GC with an inert XL $\mathrm{EI} / \mathrm{CI}$ MSD EPCPTV injector at $250^{\circ} \mathrm{C}$, splitless. Helium carrier gas was $1.3 \mathrm{ml} / \mathrm{min}$ at constant flow. Columns used were: SPB-1 $60 \mathrm{~m} \times 0.25 \mathrm{~mm}$ (id) $\times 0.25 \mu \mathrm{m}$ (film) $\left(\right.$ Supelco $^{\circledR}$, Bellefonte, Pennsylvania, USA) and a J\&W DB-5MS ${ }^{\circledR}, 60 \mathrm{~m} \times 0.25 \mathrm{~mm}$ (id) $\times 0.25 \mu \mathrm{m}$ (film) and a HP-INNOWAX $^{\circledR}, 60 \mathrm{~m} \times 0.25 \mathrm{~mm}$ (id), $\times 0.25 \mu \mathrm{m}$ (film). The temperature program for the SPB-1 and J\&W-5MS was an initial oven temperature of $50^{\circ} \mathrm{C}$ was held for 3 min then increased at $5^{\circ} \mathrm{C} / \mathrm{min}$ to $210^{\circ} \mathrm{C}$. This temperature was maintained for $25 \mathrm{~min}$. The HP-INNOWAX column was programmed as reported previously [14] with an initial temperature of $40^{\circ} \mathrm{C}$ for $1 \mathrm{~min}, 16^{\circ} \mathrm{C} / \mathrm{min}$ to $80^{\circ} \mathrm{C}$, and $7^{\circ} \mathrm{C} / \mathrm{min}$ to $230^{\circ} \mathrm{C}$ and held for $10 \mathrm{~min}$. Carrier gas (helium) for this column was $1.0 \mathrm{ml} / \mathrm{min}$, constant flow.

Additional confirmation of the chemical identity was done using a Varian Saturn $2000 \mathrm{GC} / \mathrm{MS} / \mathrm{MS}$ with a 30 $\mathrm{m} \times 0.25 \mathrm{~mm} \times 0.25 \mu \mathrm{m}$, RTX-5Sil MS (Restex, Bellefonte, Pennsylvania, USA) column. The injector was split/splitless 1079 injector isothermal at $250^{\circ} \mathrm{C}$. Helium carrier was $1.2 \mathrm{ml} / \mathrm{min}$ (constant flow) and the oven initial temperature was $50^{\circ} \mathrm{C}$ for $2 \mathrm{~min}$, increased $10^{\circ} \mathrm{C} / \mathrm{min}$ to $130^{\circ} \mathrm{C}$, and then increased at $20^{\circ} \mathrm{C} / \mathrm{min}$ to $210^{\circ} \mathrm{C}$. Both electron impact and chemical ionization using isobutene were obtained with the Varian spectrometer. Identity of the sesquiterpenes was based on published reports [14, 22] and comparison of spectra with the NIST library (Gaithersburg, Maryland, USA) and the mass spectra and retention times with those of corresponding reference samples contained in our EI and CI library. Percentage of compounds was based on the response of the flame ionization detector to the compound using gas chromatography. Generally, the sesquiterpenes that were used for analysis were based on a representative selection of chemicals having the largest peak area and occurred in greater than three percent in at least one of the genotypes being compared. 


\subsection{Statistical Analysis}

Comparisons of percentage of each volatile chemical as determined by SPME versus Super-Q were done using two sample $t$-tests [23], with separate analysis for each chemical. An $F$-test was conducted using Excel to compare sample variance for each technique, with separate tests for each chemical. For comparison of chemical profiles from different parts of the tree, samples were divided into groups including leaf, branch and trunk. Twosample analysis of variance (ANOVA) with interaction using Proc GLM [23] was used to test the effect of genotype (3 levels) and sample group (3 levels). Significant ANOVAs were followed by least significant difference test (LSD, $P<0.05$ ) for mean separation. The BoxCox procedure, which is a power transformation that regresses log-transformed standard deviations $(y+1)$ against log-transformed means $(x+1)$, was used to determine the type of transformation necessary to stabilize the variance before analysis [24]. Separate analyses were run for data from each chemical.

Differences in ratios of the chemicals as the diameter of the branch increased from smallest $(0.8 \mathrm{~cm})$ to the widest branch sampled $(5.1 \mathrm{~cm})$ were tested with regression using indicator variables [25]. Indicator variables were used to compare sequential groupings of branch diameters to determine a hypothetical break point at which the regression line changed slope [26,27]. This was done by creating a series of indicator variables that were coded with a 1 for diameters to be included and with a 0 for diameters to be excluded in the analysis. For example, coding samples $0.8 \mathrm{~cm}$ with a 0 and all other samples with a 1 allowed comparisons between the narrowest branch sample and all other branch samples. Four indicator variables were created, and these indicator variables were entered sequentially until the regression model with the largest $R^{2}$ was found, using Proc REG [23].

\section{Results}

\subsection{Comparison of SPME and Super-Q Collections}

Sesquiterpenes (that comprised at least $3 \%$ of the volatile chemical profile) identified from leaves of the first "Melendez" seedling included $\alpha$-cubebene, $\alpha$-copaene, $\beta$-cubebene, $\beta$-caryophyllene, $\alpha$-humulene, and cadinene. All chemicals were obtained using both SPME and collection on Super-Q. SPME gave a higher percentage of $\alpha$-cubebene than Super-Q $(15.3 \pm 1.3$ and $12.5 \pm 0.5 ; t=$ $2.7, \mathrm{df}=8, P=0.0258)$, but there were no differences in percentages of the other chemicals. SPME tended to have higher variance (less consistency) than Super-Q collections, but these differences were not significant $(P<$
0.05). Based on these results and the convenience of using SPME, SPME was used for all subsequent collections.

\subsection{Branch Cross-Section Samples}

Analysis of shavings from cross-sections of branches found that an average ( \pm std dev) of $98.4 \% \pm 0.03 \%$ of the sesquiterpenes were found in the cambial layers, and only small amounts in the sub-cambial area. Changes in color between the cambial area and the pith facilitated sampling only cambial layers, so subsequent collections from branch material were made on shavings from the cambial zone.

\subsection{Comparisons of Plant Material from Three Genotypes}

In addition to the six chemicals identified from leaves of the first "Melendez" seedling (see above), there were two chemicals identified from analysis of the other tree samples. These included alloaromadendrene and bergamotene. For all eight chemicals identified, there were significant interactions between source of sample and tree genotype. Because tree genotype was the primary factor of interest, data for the different plant material sources and chemicals were analyzed individually using separate one-way ANOVAs.

The sesquiterpenes in avocado leaves and the percentages of each are given in Table 1. There were differences in both the number of chemicals present and the ratio of those chemicals among the three genotypes. The "Melendez" seedling used for this comparison had seven sesquiterpenes, "Simmonds" had six and "Seedless Mexican" had only four. However, the most common chemical in leaves was $\beta$-caryophyllene and there were no differences in percentages among the three genotypes. There were differences in percentages of four of the remaining chemicals. The "Melendez" seedling had the highest percentage of $\alpha$-humulene, and "Simmonds" had the highest percentage of $\alpha$-cubebene. For $\alpha$-copaene, the "Seedless Mexican" had the highest percentage, Simmonds had an intermediate percentage and "Melendez" seedling the lowest percentage. "Seedless Mexican" also had the highest percentage of cadinene.

Two-way ANOVA on genotype (3 levels) and branch diameter ( 5 levels) with interaction found interactions between the two factors for most of the chemicals. Regression analysis with indicator variables found that, for most of the chemicals, the highest $R^{2}$ was obtained when samples were divided into small branch $(0.8$ to $1.3 \mathrm{~cm}$ diam) and large branch (2.54 to $5.1 \mathrm{~cm}$ diam) subgroups. For example, regression using that indicator variable had an $R^{2}=92 \%$ when $\alpha$-copaene from $0.8-1.3 \mathrm{~cm}$ branch samples were compared with amount from $2.54-5.1 \mathrm{~cm}$ 
Table 1. Percentage (mean \pm S.D.) of sesquiterpenes obtained in volatile collections using SPME from leaves of three avocado genotypes ${ }^{1}$.

\begin{tabular}{|c|c|c|c|c|c|}
\hline Chemical $^{2}$ & "Seedless Mexican" & "Simmonds" & "Melendez" & $F$ & $P$ \\
\hline$\alpha$-humulene ${ }^{3}$ & $0.0 \pm 0.0^{\mathrm{b}}$ & $4.0 \pm 0.2^{\mathrm{a}}$ & $25.2 \pm 31.0^{\mathrm{a}}$ & 12.15 & 0.0078 \\
\hline$\alpha$-copaene ${ }^{3}$ & $23.6 \pm 3.2^{\mathrm{a}}$ & $8.4 \pm 0.4^{b}$ & $4.8 \pm 1.3^{\mathrm{c}}$ & 73.51 & $<0.0001$ \\
\hline$\alpha$-cubebene ${ }^{4}$ & $0.0 \pm 0.0^{\mathrm{b}}$ & $13.0 \pm 0.7^{\mathrm{a}}$ & $2.1 \pm 1.9^{b}$ & 40.55 & 0.0003 \\
\hline cadinene $^{4}$ & $6.2 \pm 1.9^{\mathrm{a}}$ & $0.0 \pm 0.0^{\mathrm{b}}$ & $0.3 \pm 0.6^{\mathrm{b}}$ & 41.48 & 0.0003 \\
\hline$\beta$-caryophyllene ${ }^{4}$ & $44.8 \pm 4.1$ & $41.4 \pm 1.1$ & $47.6 \pm 33.8$ & 0.02 & $\mathrm{~ns}$ \\
\hline$\beta$-cubebene ${ }^{3}$ & $8.1 \pm 1.4$ & $11.3 \pm 0.6$ & $4.9 \pm 4.2$ & 1.92 & $\mathrm{~ns}$ \\
\hline bergamotene ${ }^{3}$ & $0.0 \pm 0.0$ & $3.0 \pm 2.6$ & $2.1 \pm 2.8$ & 1.70 & $\mathrm{~ns}$ \\
\hline
\end{tabular}

${ }^{1} \mathrm{n}=3, \mathrm{df}=2,6$ for all chemicals; ${ }^{2}$ Chemicals not found in leaf samples that were found in other samples: alloaromadendrene; ${ }^{3}$ Means followed by the same letter are not significantly different (LSD mean separation test on $\log (x+1)$ transformed data, $(P=0.05)$; non-transformed means presented); ${ }^{4}$ Means followed by the same letter are not significantly different (LSD mean separation test on square-root $(x+0.5)$ transformed data, $(P=0.05)$; non-transformed means presented).

branch samples, compared with $82 \%$ for the next best indicator variable. Thus, groupings by small versus large branch samples were used for subsequent analyses.

Table 2 presents the chemicals and percentages from the small $(0.8-1.3 \mathrm{~cm})$ branch samples. Seven sesquiterpenes were obtained and identified from collections of small branches, but there were differences in both types and percentages of the chemicals among the genotypes. "Seedless Mexican" had the most diversity, with seven chemicals present. The "Melendez" seedling had six sesquiterpenes, and "Simmonds" had five. Table 3 presents the chemicals and percentages from the large $(2.54-5.1 \mathrm{~cm})$ branch samples. Six sesquiterpenes were identified from these branches and there were differences in not only type but also percentage of chemicals among the genotypes. "Seedless Mexican" had the highest percentage of $\alpha$-copaene, cadinene and $\beta$-caryophyllene among the three genotypes, and these three chemicals represented $80 \%$ of the sesquiterpene content in the branch. $\alpha$-Copaene was also the major sesquiterpene present in "Simmonds" and "Melendez" seedling. $\alpha$ Copaene concentrations in the different genotypes was quantified using Super-Q collections made from shavings $(6 \mathrm{~g})$ of branches $(2.54$ to $5.1 \mathrm{~cm}$ diam). Average $( \pm$ std dev) amount of $\alpha$-copaene present in material from large branches was $5.7( \pm 2.8), 6.2( \pm 1.5)$ and $1.8( \pm 1.9) \mu \mathrm{g}$ in "Seedless Mexican", "Simmonds" and "Melendez" seedling, respectively.

Table 4 presents the chemicals and percentages from the trunk samples. Six sesquiterpenes were obtained from trunk collections. All three trees contained $\alpha$-copaene, $\alpha$-cubebene, $\beta$-caryophyllene, $\beta$-cubebene. There were no differences in percentages among the genotypes, and $\alpha$-copaene was the major component in all three trees. There were differences observed for some of the sesquiterpenes in trunk material, due to presence in only one or two of the trees (cadinene) or different percentages in the two trees in which they were present (alloaromadendrene).

\subsection{Comparisons of Manuka Oil and Avocado Branch Chemicals}

A total of eight sesquiterpenes were detected in the combined analyses of manuka oil and large branch samples from the three avocado genotypes (Figure 1). There were no differences in chemicals emitted from the commercial manuka lure versus the neat material. The major component in manuka oil was calamenene, followed by $\alpha$-copaene. In contrast, only trace amounts of calamenene were detectable in avocado, and $\alpha$-copaene was the primary peak in all three genotypes. There were five sesquiterpenes found in common to manuka oil and all three avocado genotypes, consisting of $\alpha$-cubebene, $\alpha$-copaene, $\beta$-cubebene, $\beta$-caryophyllene, and cadinene. Estragole and anethole were not detected in any of the samples, and "Simmonds" lacked alloaromadendrene.

\section{Discussion}

Previous studies have determined chemical profiles of avocado plant material; however, most have used GC analysis of steam distilled and/or solvent extracted plant material from leaves or fruit. Steam distillation of avocado leaves found that estragole, 1-decyl acetate, and an unidentified compound occurred in and were indicative of pure or hybrid Mexican cultivars, but found no chemicals unique to Guatemalan or West Indian races $[18,28]$. Pentanediethylether extracts of fresh leaves of a Mexican race avocado tree identified thirty compounds that accounted for $92.5 \%$ of the avocado leaf oil chemicals [29]. In that study, estragole was the major component $(78.1 \%)$, followed by $\alpha$-cubebene (3.6\%), methyl 
Table 2. Percentage (mean \pm S.D.) of sesquiterpenes obtained in volatile collections using SPME from small branch (0.8 to 1.3 cm diam.) samples of three avocado genotypes ${ }^{1}$.

\begin{tabular}{|c|c|c|c|c|c|}
\hline Chemical $^{2}$ & "Seedless Mexican" & "Simmonds" & "Melendez" & $F$ & $P$ \\
\hline$\alpha$-humulene ${ }^{3}$ & $1.3 \pm 2.1$ & $0.0 \pm 0.0$ & $2.2 \pm 2.5$ & 2.11 & ns \\
\hline$\alpha$-copaene ${ }^{3}$ & $29.8 \pm 10.2$ & $24.3 \pm 9.4$ & $26.0 \pm 7.8$ & 0.57 & ns \\
\hline$\alpha$-cubebene ${ }^{4}$ & $3.3 \pm 1.7^{\mathrm{b}}$ & $17.3 \pm 6.2^{\mathrm{a}}$ & $12.4 \pm 2.6^{\mathrm{a}}$ & 24.28 & $<0.0001$ \\
\hline alloaromadendrene ${ }^{4}$ & $2.2 \pm 2.6^{\mathrm{b}}$ & $0.0 \pm 0.0^{\mathrm{c}}$ & $6.1 \pm 3.1^{\mathrm{a}}$ & 13.63 & 0.0004 \\
\hline cadinene $^{4}$ & $7.8 \pm 1.2^{\mathrm{a}}$ & $2.1 \pm 2.4^{\mathrm{b}}$ & $0.0 \pm 0.0^{\mathrm{c}}$ & 31.27 & $<0.0001$ \\
\hline$\beta$-caryophyllene ${ }^{4}$ & $35.0 \pm 7.2^{\mathrm{a}}$ & $13.1 \pm 6.0^{\mathrm{b}}$ & $18.9 \pm 9.7^{b}$ & 11.19 & 0.0011 \\
\hline$\beta$-cubebene ${ }^{3}$ & $10.5 \pm 2.2^{\mathrm{b}}$ & $13.1 \pm 2.3^{\mathrm{a}}$ & $9.9 \pm 0.7^{\mathrm{b}}$ & 5.18 & 0.0194 \\
\hline
\end{tabular}

${ }^{1} \mathrm{n}=3$, df $=2,15$ for all chemicals; ${ }^{2}$ Chemical not found in samples from small branches that were found in other samples: bergamotene; ${ }^{3}$ Means followed by the same letter are not significantly different (LSD mean separation test on $\log (x+1)$ transformed data, $(P=0.05)$; non-transformed means presented); ${ }^{4}$ Means followed by the same letter are not significantly different (LSD mean separation test on square-root $(x+0.5)$ transformed data, $(P=0.05)$; non-transformed means presented).

Table 3. Percentage (mean \pm S.D.) of sesquiterpenes obtained in volatile collections using SPME from large branch (2.54 to $5.1 \mathrm{~cm}$ diam.) samples of three avocado genotypes ${ }^{1}$.

\begin{tabular}{|c|c|c|c|c|c|}
\hline Chemical $^{2}$ & "Seedless Mexican" & "Simmonds" & "Melendez" & $F$ & $P$ \\
\hline$\alpha$-copaene ${ }^{3}$ & $56.2 \pm 9.9^{\mathrm{a}}$ & $29.3 \pm 2.5^{\mathrm{b}}$ & $29.9 \pm 1.9^{b}$ & 77.33 & $<0.0001$ \\
\hline$\alpha$-cubebene ${ }^{4}$ & $4.1 \pm 0.6^{\mathrm{b}}$ & $9.1 \pm 1.3^{\mathrm{a}}$ & $9.2 \pm 2.2^{\mathrm{a}}$ & 42.93 & $<0.0001$ \\
\hline alloaromadendrene $e^{4}$ & $3.1 \pm 0.6^{\mathrm{b}}$ & $0.0 \pm 0.0^{\mathrm{c}}$ & $9.4 \pm 0.9^{\mathrm{a}}$ & 792.60 & $<0.0001$ \\
\hline cadinene $^{4}$ & $7.9 \pm 1.3^{\mathrm{a}}$ & $0.0 \pm 0.0^{\mathrm{b}}$ & $0.0 \pm 0.0^{\mathrm{b}}$ & 780.36 & $<0.0001$ \\
\hline$\beta$-caryophyllene ${ }^{4}$ & $16.5 \pm 8.3^{\mathrm{a}}$ & $8.4 \pm 1.0^{\mathrm{b}}$ & $6.5 \pm 1.6^{\mathrm{b}}$ & 13.25 & 0.0001 \\
\hline$\beta$-cubebene ${ }^{3}$ & $6.3 \pm 1.8^{\mathrm{c}}$ & $12.1 \pm 1.1^{\mathrm{a}}$ & $10.0 \pm 0.8^{\mathrm{b}}$ & 37.79 & $<0.0001$ \\
\hline
\end{tabular}

${ }^{1} \mathrm{n}=3, \mathrm{df}=2,24$ for all chemicals; ${ }^{2}$ Chemicals not found in samples from large branches that were found in other samples: $\alpha$-humulene, bergamotene; ${ }^{3}$ Means followed by the same letter are not significantly different (LSD mean separation test on $\log (x+1)$ transformed data, $(P=0.05)$; non-transformed means presented); ${ }^{4}$ Means followed by the same letter are not significantly different (LSD mean separation test on square-root $(x+0.5)$ transformed data, $(P=0.05)$; non-transformed means presented).

Table 4. Percentage (mean \pm S.D.) of sesquiterpenes obtained in volatile collections using SPME from trunk samples of three avocado genotypes ${ }^{1}$.

\begin{tabular}{|c|c|c|c|c|c|}
\hline Chemical $^{2}$ & "Seedless Mexican" & "Simmonds" & "Melendez" & $F$ & $P$ \\
\hline$\alpha$-copaene ${ }^{3}$ & $67.1 \pm 6.0$ & $40.1 \pm 6.0$ & $22.2 \pm 19.3$ & 4.19 & $\mathrm{~ns}$ \\
\hline$\alpha$-cubebene ${ }^{3}$ & $3.6 \pm 2.4$ & $6.8 \pm 1.0$ & $5.8 \pm 1.3$ & 2.80 & ns \\
\hline alloaromadendrene ${ }^{3}$ & $5.0 \pm 1.7^{\mathrm{b}}$ & $0.0 \pm 0.0^{c}$ & $9.6 \pm 0.6^{\mathrm{a}}$ & 110.54 & $<0.0001$ \\
\hline cadinene $^{3}$ & $8.4 \pm 3.8^{\mathrm{a}}$ & $0.0 \pm 0.0^{\mathrm{b}}$ & $0.0 \pm 0.0^{\mathrm{b}}$ & 35.76 & 0.0005 \\
\hline$\beta$-caryophyllene ${ }^{3}$ & $2.3 \pm 1.4$ & $3.4 \pm 0.2$ & $1.9 \pm 0.4$ & 2.56 & ns \\
\hline$\beta$-cubebene ${ }^{4}$ & $4.2 \pm 3.4$ & $9.5 \pm 1.9$ & $9.4 \pm 0.4$ & 4.53 & ns \\
\hline
\end{tabular}

${ }^{1} \mathrm{n}=3, \mathrm{df}=2,6$ for all chemicals; ${ }^{2}$ Chemicals not found in samples from trunks that were found in other samples: $\alpha$-humulene, bergamotene; ${ }^{3}$ Means followed by the same letter are not significantly different (LSD mean separation test on square-root $(x+0.5)$ transformed data, $(P=0.05)$; non-transformed means presented); ${ }^{4}$ Means followed by the same letter are not significantly different (LSD mean separation test on log $(x+1)$ transformed data, $(P=0.05)$; non-transformed means presented). 


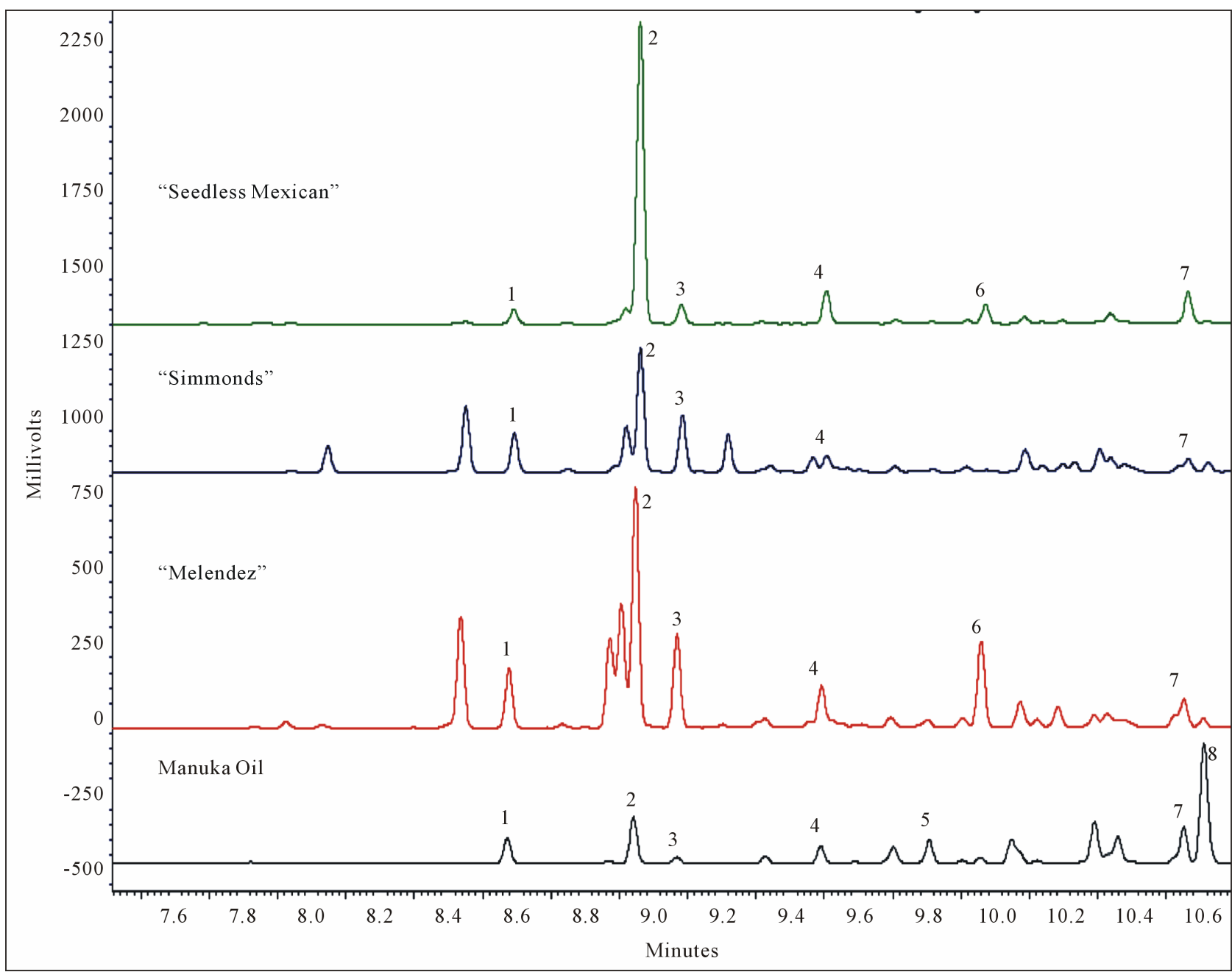

Figure 1. Representative GC analyses of sesquiterpenes obtained by SPME collections from manuka oil and avocado branches $\geq 2.5 \mathrm{~cm}$ diam. Only sesquiterpenes comprising at least $3 \%$ of the volatile chemical profile are labeled. Peak identifications are as follows: $1: \alpha$-cubebene, 2 : $\alpha$-copaene, 3: $\beta$-cubebene, 4 : $\beta$-caryophyllene, 5: $\alpha$-humulene, 6: alloaromadendrene, 7: cadinene, 8: calamenene.

eugenol (3.47\%) and $\beta$-caryophyllene (2.1\%). Steam distilled/pentane extracts of avocado fruit (unknown variety) found mostly $\beta$-caryophyllene (60\%) followed by $\alpha$-humulene [5.9\%]), caryophyllene oxide $(4.5 \%), \alpha$ copaene (4.5\%) and $\alpha$-cubebene [30]. Soxhlet extraction with methane of "Hess" (race unknown) and "Fuerte" (Guatemalan/West Indian hybrid) found eight chemicals and twenty two chemicals, respectively [31]. These included $\beta$-caryophyllene in both genotypes, elemene in "Hess", and cadinene and $\alpha$-humulene in "Fuerte" fruit; but the amounts were not quantified. An evaluation of four extraction methods found that chemical profiles obtained from avocado fruit varied according to the extraction method, and it was speculated that this was due to oxidation caused by solvents [32].

Volatile collections made from minced leaves of "Hass" (Guatemala/West Indian hybrid) and "Criollo" (Mexican race) avocado trees using charcoal traps [33] indicated that estragole (54.7\%), $\alpha$-pinene (16.3\%) and $\beta$ pinene (14.2\%) were the primary components in "Criollo" leaves, whereas $\beta$-caryophyllene (19.7\%), $\beta$-pinene $(18.5 \%)$ and $\alpha$-pinene $(18.5 \%)$ predominated in "Hass". Volatile collections from detached branches that were artificially infested with late instar larvae of the avocado stem weevil, Copturus aguacatae Kissinger (Coleoptera: Curculionidae), found that few chemicals were emitted from either infested or non-infested "Hass" samples, but chemical emission decreased when infested "Criollo" samples were compared to non-infested samples [33].

We compared SPME headspace collections from minced leaves of two replicate trees each of avocado trees representing all three races and all hybrid crosses (12 genotypes; RRH and EQS, unpublished data). As was reported previously [18,28], there were large amounts of estragole in Mexican race trees, but no volatile sesquiterpenes could distinguish between the Guate- 
malan or West Indian races. Since few Mexican cultivars but several Mexican hybrids lacked estragole [18], the "Seedless Mexican" sampled in this study may be a Mexican hybrid and not a pure Mexican race avocado. There was high variation in leaf chemical profile within and among the twelve genotypes sampled, which makes it difficult to use chemical profile from leaves to characterize avocado genotype. Furthermore, the chemical content of leaves was not indicative of chemical content in branches and trunks, the site of RAB attack. Thus leaf samples, although easy to obtain, do not provide useful chemotaxonomic information nor do they serve as a good source for identification of semiochemicals for RAB.

Similarly, there was high variation that limited the usefulness of sesquiterpene chemical content as determined from small branches $(<2.5 \mathrm{~cm}$ diameter $)$; and percentages quantified were intermediate between those obtained with leaf samples and large branch samples. For example, small branches had a higher percentage of $\alpha$ copaene than leaf samples, but still had fairly high levels of $\beta$-caryophyllene. Although there were fewer sesquiterpenes present in the large branches as compared to the small branches, there were significant differences among the genotypes for all of the chemicals. Analysis of the trunk samples indicated that this material provides less chemotaxonomic information than the large branch samples, with significant differences observed for only two sesquiterpenes within the trunk.

The major sesquiterpene common to large diameter branches and trunks from all avocado cultivars was $\alpha$ copaene. In two initial field evaluations of RAB attraction to freshly-cut ( $5 \mathrm{~cm}$ diam.) bolts of avocado, it was found that beetle captures were positively correlated with emissions of several sesquiterpenes, including $\alpha$-copaene [15]. Those same tests evaluated cultivars representative of the three horticultural races ("Simmonds", West Indian; "Brooks Late", Guatemalan; and "Seedless Mexican", Mexican), and found no statistical difference in RAB captures among races, but the Mexican cultivar caught fewer RAB in both field tests. Further testing is needed with additional (Mexican) cultivars to assess if there are genetically-based chemical differences among avocado cultivars which may potentially confer them less attractive to the beetle vector. In addition, female RAB typically initiate boring in the trunk and large diameter branches of host trees. In a survey of swampbay trees with laurel wilt $(\mathrm{N}=280)$, no RAB entry holes were observed in trunks/branches less than $\sim 2 \mathrm{~cm}$ diameter, and there was a progressive increase in density of RAB entry holes with increasing diameter [12]. This observation indicates that host-seeking RAB have a diameter preference, which may potentially be assessed by means of a visual cue, by proximo-distal gradients in sesquiterpene content related to branch/trunk diameter, or by a combi- nation of both visual and chemical cues.

The goal of this research was to develop a protocol for sampling avocado plant material for future studies on 1) chemotaxonomy of avocado, which may provide improved methods of assigning a cultivar to a race [28]; and 2) identification of host volatiles that may function as semiochemicals for RAB [34]. Based on data obtained from avocado genotypes representative of the known horticultural races, it is recommended that samples for chemical analysis be collected from branches $\geq 2.5 \mathrm{~cm}$ in diameter. This diameter is also consistent with field observations for site of RAB attack. The findings reported herein indicate that many of the volatiles emitted from manuka oil are also present in avocado wood material. Our analyses suggest that $\alpha$-copaene is likely the primary host attractant in avocado since calamenene is present in only very limited quantities. Insight into potential RAB attractants may be gained from comparative studies of known RAB host plants, including analysis of sesquiterpene content and evaluation of relative attractiveness in field tests or laboratory bioassays. However, identification of specific RAB kairomones may be greatly facilitated by combining the chemical sampling methods outlined in this report with a newly developed electroantennography method used to directly quantify the olfactory response from antennae of RAB [35].

\section{Acknowledgements}

The authors thank Tomás Ayala-Silva, Wayne Montgomery, Mike Moore, and Mike Winterstein (USDAARS, Miami, FL) for helpful discussions related to this research. Support was provided in part by the USDAARS National Plant Disease Recovery System and the Florida Avocado Administrative Committee. This report presents the results of research only; mention of a proprietary product does not constitute an endorsement by the USDA.

\section{REFERENCES}

[1] H. Y. Nakasone and R. E. Paull, "Tropical Fruits," CAB International, Wallingford, 1998.

[2] E. Evans and S. Nalampang, "World, US and Florida Avocado Situation and Outlook," 2006. http://edis.ifas.ufl.edu/pdffiles/FE/FE63900.pdf

[3] USDA-ARS National Genetic Resources Program, "Germplasm Resources Information Network (GRIN)," National Germplasm Resources Laboratory, Beltsville, 2005. http://www.ars-grin.gov/cgi-bin/npgs/html/site.pl?MIA

[4] R. J. Schnell, J. S. Brown, C. T. Olano, E. J. Power and C. A. Krol, "Evaluation of Avocado Germplasm Using Microsatellite Markers," Journal of the American Society for Horticultural Science, Vol. 128, No. 6, 2003, pp. 881889.

[5] W. Popenoe, "Manual of Tropical and Subtropical Fruits," 
Macmillan, New York, 1920.

[6] A Ben-Ya'acov, "The Taxonomy of the Avocado: A Proposed New classification of the Persea Sub-genus Persea," Proceedings of the 3rd World Avocado Congress, Tel Aviv, 22-27 October 1995, p. 75.

[7] S. W. Fraedrich, T. C. Harrington, R. J. Rabaglia, M. D. Ulyshen, A. E. Mayfield III, J. L. Hanula, J. M. Eickwort and D. R. Miller, "A Fungal Symbiont of the Redbay Ambrosia Beetle Causes a Lethal Wilt in Redbay and Other Lauraceae in the Southeastern United States," Plant Disease, Vol. 92, No. 2, 2008, pp. 215-224. doi:10.1094/PDIS-92-2-0215

[8] T. C. Harrington, S. W. Fraedrich and D. N. Aghayeva, "Raffaelea lauricola, a New Ambrosia Beetle Symbiont and Pathogen on the Lauraceae," Mycotaxon, Vol. 104, No. 2, 2008, pp. 399-404.

[9] United States Department of Agriculture, Forest Service, Forest Health Protection, Southern Region, "Laurel Wilt Distribution," 2012.

http://www.fs.fed.us/r8/foresthealth/laurelwilt/dist_map.s html

[10] Florida Department of Agriculture and Consumer Services, "Florida Department of Agriculture and Consumer Services Identifies Laurel Wilt Disease in Avocado Production Area of Miami-Dade County, Press Release 1 May 2012," 2012.

http://www.freshfromflorida.com/newsroom/press/2012/0 5012012.html

[11] A. E. Mayfield III, J. E. Peña, J. H. Crane, J. A. Smith, C. L. Branch, E. D. Ottoson and M. Hughes, "Ability of the Redbay Ambrosia Beetle (Coleoptera: Curculionidae: Scolytinae) to Bore into Young Avocado (Lauraceae) Plants and Transmit the Laurel Wilt Pathogen (Raffaelea sp.)," Florida Entomologist, Vol. 91, No. 3, 2008, pp. 485487.

[12] P. E. Kendra, W. S. Montgomery, J. Niogret and N. D. Epsky, "An Uncertain Future for American Lauraceae: A Lethal Threat from Redbay Ambrosia Beetle and Laurel Wilt Disease (A Review)," American Journal of Plant Sciences, Vol. 4, No. 3A, 2013, pp. 727-738. doi:10.4236/ajps.2013.43A092

[13] J. L. Hanula, A. E. Mayfield III, S. W. Fraedrich and R. J. Rabaglia, "Biology and Host Associations of the Redbay Ambrosia Beetle (Coleoptera: Curculionidae: Scolytinae), Exotic Vector of Laurel Wilt Killing Redbay Trees in the Southeastern United States," Journal of Economic Entomology, Vol. 101, No. 4, 2008, pp. 1276-1286. doi:10.1603/0022-0493(2008)101[1276:BAHAOR]2.0.C $\underline{\mathrm{O} ; 2}$

[14] J. L. Hanula and B. Sullivan, "Manuka Oil and Phoebe Oil Are Attractive Baits for Xyleborus glabratus (Coleoptera: Curculionidae: Scolytinae), the Vector of Laurel Wilt," Environmental Entomology, Vol. 37, No. 6, 2008, pp. 1403-1409. doi:10.1603/0046-225X-37.6.1403

[15] P. E. Kendra, W. S. Montgomery, J. Niogret, J. E. Peña, J. L. Capinera, G. Brar, N. D. Epsky and R. R. Heath, "Attraction of the Redbay Ambrosia Beetle, Xyleborus glabratus, to Avocado, Lychee, and Essential Oil Lures," Journal of Chemical Ecology, Vol. 37, No. 9, 2011, pp.
932-942.

[16] P. E. Kendra, J. Niogret, W. S. Montgomery, J. S. Sanchez, M. A. Deyrup, G. E. Pruett, R. C. Ploetz, N. D. Epsky and R. R. Heath, "Temporal Analysis of Sesquiterpene Emissions from Manuka and Phoebe Oil Lures and Efficacy for Attraction of Xyleborus glabratus (Coleoptera: Curculionidae: Scolyinae)," Journal of Economic Entomology, Vol. 105, No. 2, 2012, pp. 659-669. doi: $10.1603 / \mathrm{EC} 11398$

[17] N. G. Porter and A. L. Wilkins, "Chemical, Physical and Antimicrobial Properties of Essential Oils of Leptospermum scoparium and Kunzea ericoides," Phytochemistry, Vol. 50, No. 3, 1998, pp. 407-415. doi:10.1016/S0031-9422(98)00548-2

[18] J. R. King and R. J. Knight, "Occurrence and Assay of Estragole in the Leaves of Various Avocado Cultivars," Journal of Agricultural and Food Chemistry, Vol. 35, No. 5, 1987, pp. 842-844. doi:10.1021/jf00077a048

[19] J. Crane and M. Mossler, "Crop Profile for Avocados in Florida," 2008.

http://www.ipmcenters.org/cropprofiles/docs/FLavocados. pdf

[20] R. R. Heath, A. Manukian, N. D. Epsky, J. Sivinski, C. O. Calkins and P. J. Landolt, "A Bioassay System for Collecting Volatiles While Simultaneously Attracting Tephritid Fruit Flies," Journal of Chemical Ecology, Vol. 19, No. 10, 1993, pp. 2395-2410. doi:10.1007/BF00979673

[21] R. R. Heath and A. Manukian, "Development and Evaluation of Systems to Collect Volatile Semiochemicals from Insects and Plants Using a Charcoal-Infused Medium for Air Purification," Journal of Chemical Ecology, Vol. 18, No. 7, 1992, pp. 1209-1226. doi:10.1007/BF00980075

[22] D. J. Crook, A. Khrimian, J. A. Francese, I. Fraser, T. M. Poland, A. J. Sawyer and V. C. Mastro, "Development of a Host-Based Semiochemical Lure for Trapping Emerald Ash Borer Agrilus planipennis (Coleoptera: Buprestidae), Environmental Entomology, Vol. 37, No. 2, 2008, pp. 356-365.

doi:10.1603/0046-225X(2008)37[356:DOAHSL]2.0.CO;2

[23] SAS Institute, "SAS/STAT Guide for Personal Computers, Version 8.2," SAS Institute, Cary, 2001.

[24] G. E. P. Box, W. G. Hunter and J. S. Hunter, "Statistics for Experimenters. An Introduction to Design, Data Analysis, and Model Building," John Wiley \& Sons, New York, 1978.

[25] J. H. Zar, "Biostatistical Analysis," 4th Edition, Prentice Hall, Upper Saddle, 1999.

[26] J. L. Capinera, D. R. Horton, N. D. Epsky and P. L. Chapman, "Effects of Plant Density and Late-Season Defoliation on Yield of Field Beans," Environmental Entomology, Vol. 16, No. 1, 1987, pp. 274-280.

[27] P. E. Kendra, W. S. Montgomery, D. M. Mateo, H. Puche, N. D. Epsky and R. R. Heath, "Effect of Age on EAG Response and Attraction of Female Anastrepha suspensa (Diptera: Tephritidae) to Ammonia and Carbon Dioxide," Environmental Entomology, Vol. 34, No. 3, 2005, pp. 584-590. doi:10.1603/0046-225X-34.3.584

[28] J. R. King and R. J. Knight, "Volatile Components of the 
Leaves of Various Avocado Cultivars," Journal of Agricultural and Food Chemistry, Vol. 40, No. 7, 1992, pp. 1182-1185. doi:10.1021/jf00019a020

[29] L. Sagrero-Nieves and J. P. Bartley, "Volatile Components of Avocado Leaves (Persea americana Mill.) from the Mexican Race," Journal of the Science of Food and Agriculture, Vol. 67, No. 1, 1995, pp. 49-51. doi:10.1002/jsfa.2740670109

[30] S. Sinyinda and J. W. Gramshaw, "Volatiles of Avocado Fruit," Food Chemistry, Vol. 62, No. 4, 1998, pp. 483487. doi:10.1016/S0308-8146(97)00190-8

[31] S. N. Azizi and S. Najafzadeh, "Fatty Acids and Volatile Compounds in Avocado Cultivated in North of Iran," World Applied Sciences Journal, Vol. 5, No. 1, 2008, pp. $1-4$.

[32] A. Ortiz Moreno, L. Dorantes, J. Galídez and R. I. Guzmán, "Effect of Different Extraction Methods on Fatty Acids, Volatile Compounds, and Physical and Chemical Properties of Avocado (Persea americana Mill.) Oil,"
Journal of Agricultural and Food Chemistry, Vol. 51, No. 8, 2003, pp. 2216-2221. doi:10.1021/jf0207934

[33] A. E. Bravo-Monzón and F. J. Espinosa-García, "Volatile Emissions in Persea americana in Response to the Stem Borer Copturus agacatae Attack," Allelopathy Journal, Vol. 21, No. 1, 2008, pp. 165-173.

[34] J. Niogret, P. E. Kendra, N. D. Epsky and R. R. Heath, "Comparative Analysis of Terpenoid Emissions from Florida Host Trees of the Redbay Ambrosia Beetle, $X y$ leborus glabratus (Coleoptera: Curculionidae: Scolytinae)," Florida Entomologist, Vol. 94, No. 4, 2011, pp. 1010-1017. doi:10.1653/024.094.0439

[35] P. E. Kendra, W. S. Montgomery, J. Niogret, M. A. Deyrup, L. Guillén and N. D. Epsky, "Xyleborus glabratus, $X$. affinis, and $X$. ferrugineus (Coleoptera: Curculionidae: Scolytinae): Electroantennogram Responses to Host-Based Attractants and Temporal Patterns in HostSeeking Flight," Environmental Entomology, Vol. 41, No. 6, 2012, pp. 1597-1605. doi:10.1603/EN12164 